TI 2017-040/I

Tinbergen Institute Discussion Paper

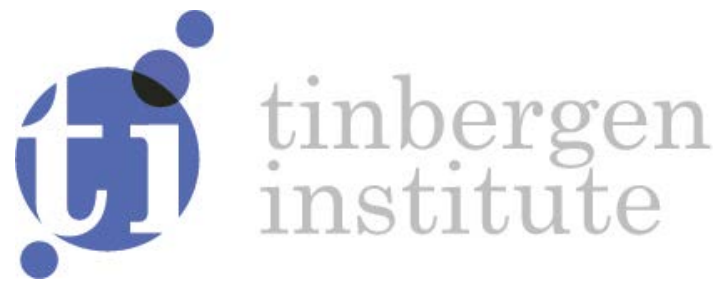

\title{
Homo Reciprocans Revisited
}

J in Di Zheng ${ }^{1}$

${ }^{1}$ CREED, University of Amsterdam 
Tinbergen Institute is the graduate school and research institute in economics of Erasmus University Rotterdam, the University of Amsterdam and VU University Amsterdam.

Contact: discussionpapers@tinbergen.nl

More TI discussion papers can be downloaded at http://www.tinbergen.nl

Tinbergen Institute has two locations:

Tinbergen Institute Amsterdam

Gustav Mahlerplein 117

1082 MS Amsterdam

The Netherlands

Tel.: $+31(0) 205984580$

Tinbergen Institute Rotterdam

Burg. Oudlaan 50

3062 PA Rotterdam

The Netherlands

Tel.: +31(0)104088900 


\title{
Homo Reciprocans Revisited
}

\author{
Jin Di Zheng*
}

April 19, 2017

\begin{abstract}
Do reciprocal workers work more if their wage compares well to similar workers in the economy? Are they more satisfied with their job? Predictions vary from theories. With a survey dataset with a representative sample of the German population, I construct a reference wage and measures for reciprocity for each worker. Depending on how much more or less a worker earns than the reference, I investigate how effort and job satisfaction react to reciprocity tendencies. The results suggest that a worker's unpaid overtime hours increase with her relative earnings if above the reference; and the more so, the stronger her positive reciprocity tendency is. However, there is no such interaction for negative reciprocity. Job satisfaction is associated with reciprocity, yet insensitive to the interaction between reciprocity and relative income. (JEL: J3, M5)
\end{abstract}

Keywords: reciprocity, effort, satisfaction, reference wage

\section{Introduction}

Reciprocity matters in the workplace. Recent field experiments have shown that employers can increase employees' productivity by giving gifts (monetary or nonmonetary) to employees. Meanwhile, employees' productivity might decrease if employers treat employees in an unkind way. The former tendency is often referred to as positive reciprocity and the latter as negative reciprocity. ${ }^{1}$ Many laboratory experiments show similar tendencies among workers to reward "generous offers" with

\footnotetext{
*University of Amsterdam, CREED. Corresponding author: jindizheng@gmail.com.

${ }^{1}$ Examples for such reciprocal reactions from employees are ample. For instance, receiving gifts from the employer increases the amount of data-entry by up to $30 \%$ in the university library (Kube et al. 2012), tree planters increase their daily productivity by $10 \%$ when they received a lump-sum of $\$ 80$ for one day in addition to their regular wage (Bellemare and Shearer, 2009), and bicycle
} 
higher effort to their employer and decrease effort when their employer pays a wage that is perceived to be unfair (see Fehr and Gächter (2000) for a review).

While reciprocal behaviours are well-documented in the laboratory and with a few controlled field experiments, evidence remains scarce whether the same holds in non-experimental settings, with diverse occupations, different social contexts, and longer time spans. In fact, evidence is mixed: some field-experimental studies suggest that reciprocal responses to kind acts may be short-lived (Gneezy and List 2006).

This paper follows Dohmen et al. (2009), who take a further empirical step by departing from the experimental settings, and studying reciprocity in a representative sample of the population. More precisely, I aim to discover how the effort a worker exerts relates to whether her wage is higher or lower than that of similar others; and in addition, how this relationship interacts with her inclinations to reciprocate. Moreover, I will investigate how job satisfaction relates to relative wage and reciprocal tendencies. Will employees with higher positive reciprocal inclinations be willing to offer more effort, if their wages are higher than the average? Does it hold that the more a worker earns than the average the more effort she will exert, compared to her peers who are equally positively reciprocal? How do these responses affect the satisfaction a worker feels with her job?

Throughout this paper I assume that individuals compare their wages to others (Festinger 1954). This requires a reference level to be used for the comparison. To this end, I use the German Socio-Economic Panel (GSOEP) to construct a reference wage for each individual based on a set of characteristics. The reference wage represents the average wage a worker with the same characteristics in the economy earns. I subsequently assume that the larger the difference between a worker's wage and messengers raise their work time by $33.5 \%$ after getting a $25 \%$ increase in the commission rate (Fehr and Goette 2007). In contrast, policemen decreased the arrest rates after experiencing an unexpected pay cut in New Jersey (Mas 2006), and one-time salesmen affected by a pay cut reduce their sales (Cohn et al. 2014). 
the reference wage is, the more generously the employer is treating a worker. I also follow Dohmen et al. (2009) and construct measures of each individual's inclinations to reciprocate others' action, both for positive and negative reciprocal tendencies. For this purpose, I use individual responses to a set of attitudinal questions posed in GSOEP. Details are provided below.

Since this paper builds on Dohmen et al. (2009) and extends their work, I shortly review their findings. Using the GSOEP dataset, Dohmen et al. (2009) investigate how a worker's reciprocal tendencies are linked to her working life, e.g., overtime work, income, job satisfaction, and personal success. To study the relationship between reciprocal tendencies and effort, the authors focus on two groups of employees, using a question in the survey about the fairness perception of their wage. ${ }^{2}$ Depending on the fairness perception, they examine how effort is related to reciprocal tendencies in both groups. Their results show that if employees perceive their wage to be fair, there is a positive correlation between positive reciprocity and the likelihood of working overtime. The relation is insignificant, however, between negative reciprocity and effort in the group where the wage is perceived to be unfair. Therefore, relying on workers' subjective perception about wage fairness, Dohmen et al. (2009) confirm - partially - the experimental findings that workers in the economy reciprocate fair wage offers by their employers.

In this paper, I adopt two continuous variables in my empirical analysis which distinguishes my work from Dohmen et al. (2009). ${ }^{3}$ First, for the dependent variable of work effort, instead of a binary variable of doing overtime or not, I choose the number of hours of unpaid overtime. This variable has the advantage of containing richer information on the amount of effort exerted by the worker. Second, and more importantly, I adopt a (continuous) measure for how well workers are treated by

\footnotetext{
${ }^{2}$ The original question in English (translated from German) is "Is the income that you earn at your current job just, from your point of view?" The questionnaire questions are available online. See GSOEP website. www.diw.de/en/soep.

${ }^{3}$ My work also distinguishes itself from Dohmen et al. (2009) by considering the effects of reciprocity and wages on job satisfaction.
} 
their employers that takes into account the heterogeneity in the worker population. In particular, it is important to take into account that what is a fair wage to one worker might not be a fair wage to another. This measure is constructed by predicting a reference wage for workers with similar characteristics. The comparison between a worker's wage and the reference allows me to shed light on how well an employee is treated by her employer compared to similar other workers in the economy. Consequently, by looking at otherwise similar workers with different reciprocal traits, we can not only observe how hard a worker works when she is treated well relative to her peers, but also investigate among equally well-treated workers how effort relates to reciprocal tendency.

My theoretical predictions about work effort are made based on reciprocity theory. A positively reciprocal worker responds to generous payments with more effort; moreover, the higher her general tendency to reciprocate is, the stronger this positive relationship will be. In contrast, a negatively reciprocal employee decreases her effort when she receives wage that is perceived to be unfair; likewise, the stronger her tendency towards negative reciprocity is, the stronger this negative relationship will be. The prediction that a positively reciprocal worker with generous wage exerts more effort is consistent with two theories. One is recorded in Levine (1998) where an altruistic employer signals her type by paying a high wage to the worker. Upon receiving the signal, the worker internalizes the employer's utility into her utility function, and thus works harder to achieve a higher joint utility. Another theory is developed by Blau (1964) where if employees are reciprocal, a generous wage gives rise to feelings of obligations on the part of the employee, which can lead to her providing higher effort.

One could argue that, even in the absence of any reciprocal tendencies, a worker's effort will be affected by other factors, such as relative wages or a threat of dismissal. To avoid being laid off, a rational and selfish worker will exert more effort when her relative wage increases, regardless of how reciprocal she is. To avoid 
shirking, the employer is paying a wage which is higher than the market clearing level. This is the efficiency wage hypothesis and was first formulated by Shapiro and Stiglitz (1984). I will argue in section 2 that, even with efficiency wages, we should still observe that reciprocal workers respond stronger to higher wages than nonreciprocal workers.

The predictions for job satisfaction are more complex than those for effort. If a worker has no reciprocal tendencies, she will experience an increase in her job satisfaction when the pay is generous. If workers do have such tendencies, however, the mechanisms may conflict, leading to an ambiguous prediction. In particular, a generous wage may go hand in hand with a higher or lower job satisfaction for workers with positive reciprocal tendencies. In some cases, for example, a worker experiences an increase of satisfaction when her employer offers a generous wage. An alternative scenario follows from Blau (1964). Workers may perceive the generous condition as a mental burden, and suffer from the perceived obligation to do extra work for the high wage.

My empirical analysis looks at the role of reciprocal tendencies on work effort and job satisfaction conditional on a worker's income relative to that of her peers. The results show that a worker exerts more effort if she compares well to her peers, and even more so if she is positively reciprocal. For example, for a worker with a high tendency - 6.88 out of 7 - towards positive reciprocity according to my measure, a 1 percent increase in her hourly wage (13 euro cents), goes with an increase of 1.8 minutes of monthly unpaid overtime. Compared to the baseline, this is a $0.45 \%$ increase. In contrast, my results show no comparable effects of negative reciprocity. More precisely, a worker with relatively low wage and strong negative reciprocity does not decrease her unpaid overtime hours than an otherwise similar worker without such reciprocal tendencies.

The analysis of job satisfaction shows that satisfaction is related to both reciprocal tendencies and relative wages. However, my data show no evidence that 
a more reciprocal worker is more satisfied with her job after a wage increase even when her wage is higher than her peers. This maybe due to the conflicting theories discussed above.

This paper adds to the literature on reciprocity in analysing the role of reciprocal inclinations in the workplace. Instead of comparing the effort levels of reciprocal workers with perceived fair or unfair wages, I use a more objective measure of how 'fair' a worker's wage is. This allows for a practical implementation of this paper's results. It suggests how employers can motivate reciprocal workers to increase productivity and effort.

The rest of the paper is organised as follows. Section 2 sets out the theoretical predictions. Section 3 introduces the data and the empirical approach. Section 4 describes the main results, and Section 5 concludes.

\section{Predictions}

Without threat of dismissal, a rational and selfish worker will not exert more effort if her wage is higher than her peers. She derives utility directly from her wages and if the utility is affected by effort, the relationship will typically be negative. If there is a threat of dismissal, a rational and selfish worker may increase her effort when she faces higher wages. In comparison, however, workers with reciprocal tendencies will respond even stronger to relative wages.

A positively reciprocal worker works more if her wage is higher than her peers; in contrast, a negatively reciprocal worker will exert less effort if she earns less than her peers. This prediction views the employment relationship as a process of exchanging favours as in social exchange theory. After receiving generous wages from the employer, employees work harder so as to return the generosity of the employer (Blau 1964). An alternative theory that assumes conditional altruism leads to the same prediction. Here, the main idea is that people are more altruistic towards those 
who are altruistic towards them, so that they internalize the other people's utility. As a consequence, employees work harder when they receive generous payments from an altruistic employer (Levine 1998). ${ }^{4}$

Following the same theories, the prediction for job satisfaction is less clear. On the one hand, according to social exchange theory, in addition to the raised job satisfaction from more income, employees may experience a decrease in their job satisfaction if the wage is generous. This is because they feel an obligation to do extra work. Therefore in this theory, the overall effect of an increase in income on job satisfaction is ambiguous. For negatively reciprocal employees, predictions for satisfaction are not mentioned in social exchange theory. Nevertheless, recent studies in neuroscience show that taking revenge brings satisfaction and deservingness to the one who punishes an unfair act (de Quervain et al. 2004; Knutson 2004; Gollwitzer et al. 2011). So, aside from the reduced satisfaction due to a low wage, workers who are negatively reciprocal might also experience an increase in job satisfaction by taking revenge on the employer (by working fewer overtime hours). Therefore the overall effect on job satisfaction for a low wage is also unclear for negatively reciprocal employees.

On the other hand, employees may experience an additional increase in their satisfaction. An altruistic worker might experience an increase in her job satisfaction when her wage is generous as she has a positive regard for the employer; in contrast, a spiteful worker will experience a reduced utility when the wage is perceived as unfair and she puts a negative regard for her employer (Levine 1998). This preference could be justified with an adjusted utility function which reflects both the worker's own utility and her regard for the employer such that the objective of individuals is to maximise their joint utility, incorporating the regards for their opponents.

\footnotetext{
${ }^{4}$ Though people might evaluate the kindness of intentions differently (Falk and Fischbacher 2006), it is generally assumed that paying a generous wage reflects good intentions in gift-exchange settings.
} 
Table 1: Theoretical predictions

\begin{tabular}{l|l|l}
\hline \hline & Positive reciprocity & Negative reciprocity \\
\hline Wage above reference & $\begin{array}{l}\text { E: }+ \\
\text { S: ? (social exchange) } \\
+ \text { otherwise }\end{array}$ & \\
& N.A. & $\begin{array}{l}\text { E: - } \\
\text { S: ? (revenge brings joy), } \\
\text { - otherwise }\end{array}$ \\
& & \begin{tabular}{l} 
Nage below reference \\
\hline
\end{tabular}
\end{tabular}

Notes: "E" stands for effort and "S" stands for satisfaction. "N.A." indicates 'not applicable'. A "+" ("-") indicates an increase (decrease) in the variable concerned. A "?" indicates that the effect is ambiguous.

To sum up in Table 1, with a higher than average wage, a positively reciprocal worker exerts more effort; and the more she earns than her peers the stronger the effect would be. With a lower wage, a negatively reciprocal worker will exert less effort; and the less she earns than her peers, the less effort we could expect from her. I do not form predictions for the interaction between positive reciprocal tendencies with lower relative wages, neither is there a prediction for the interaction between negative reciprocal tendencies with higher wages. This is because I assume that lower than average wages are not considered a 'gift' that is to be reciprocated, and, similarly, above-average wages are not considered a negative act that is to be punished. Finally, the prediction for job satisfaction derive from the interaction between social exchange theory and conditional altruism discussed above.

\section{$3 \quad$ Data and Empirical Approach}

\subsection{Data}

I use data from the German Socio-Economic Panel in the year 2005, the same dataset as in Dohmen et al. (2009). This dataset has two advantages for the study. It is a national survey and contains information on employment, health, and education from over 20,000 individuals who haven been living in Germany since $1984 .^{5}$ Also,

\footnotetext{
${ }^{5}$ For more information about the questionnaire, see the GSOEP website www.diw.de/en/soep.
} 
in 2005 for the first time, respondents were asked about reciprocity. I use the same measure of reciprocal tendencies as in Dohmen et al. (2009), which is derived from six attitudinal questions in the survey. ${ }^{6}$ Specifically, from the list of statements below, the first three hypothetical statements are related to positive reciprocity, and the other three pertain to negative reciprocity. Respondents need to indicate their attitude on a scale of 1 to 7 , ranging from "does not apply to me at all" to "applies to me perfectly". I follow Dohmen et al. (2009) and use the average scores for questions 1), 2) and 3) as a measure of the strength of positive reciprocity. Likewise, the average score for question 4), 5) and 6) provide the measure for negative reciprocity. The questions are:

1) If someone does me a favour, I am prepared to return it.

2) I go out of my way to help somebody who has been kind to me before.

3) I am ready to undergo personal costs to help somebody who helped me before.

4) If I suffer a serious wrong, I will take revenge as soon as possible, no matter what the cost.

5) If somebody puts me in a difficult position, I will do the same to him/her.

6) If somebody offends me, I will offend him/her back. ${ }^{7}$

There are approximately 20,000 respondents in the 2005 wave of the GSOEP survey. Table 2 describes the main variables of relevance for this study. On average, the respondents are 39 years old with 17 years of working experience, and 12 years of education. $37 \%$ are part-time employees, $52 \%$ are female. My analysis is restricted to employed (either full-time or part-time) respondents, excluding the self-employed, those in compulsory military or community services. This leaves me with 10,055 respondents. Respondents earn on average a (gross) hourly wage of 12.81 euro.

\footnotetext{
${ }^{6}$ In the 2010 wave, the questions on reciprocal tendencies were asked for the second time. The principal component analysis in Dohmen et al. (2009) shows that positive reciprocity and negative reciprocity are distinct traits for individuals. Positive reciprocity and negative reciprocity have a weak correlation of 0.025 . Such reciprocity measures have been used to study incentive contracts (Dur et al. 2010), trust (Dohmen et al. 2008), and job motivation (Montizaan et al. 2016).

${ }^{7}$ Those questions were translated from German, for original German questions please see www.diw.de/en/soep.
} 
Table 2: Descriptive statistics

\begin{tabular}{|c|c|c|c|c|}
\hline Variable name & Variable description & Mean & Std. & \#Obs. \\
\hline \multicolumn{5}{|l|}{ Dependent variables } \\
\hline Unpaid overtime hours & Hours of unpaid overtime last month & 6.69 & 13.21 & 9892 \\
\hline Job satisfaction & On a scale from 0 to 10 & 6.85 & 2.22 & 12189 \\
\hline \multicolumn{5}{|l|}{ Independent variables } \\
\hline Positive reciprocity & Average score on statements (from 1 to 7 ) & 5.88 & 0.91 & 20774 \\
\hline Negative reciprocity & Average score on statements (from 1 to 7 ) & 3.11 & 1.46 & 20774 \\
\hline Log of hourly gross wage & Natural logarithm of gross hourly wage & 2.55 & 0.69 & 10055 \\
\hline Hourly wage - reference & $\begin{array}{l}\text { Difference between actual wage and the } \\
\text { reference predicted by the income regression } \\
\text { (conditional on earning more than the reference wage) }\end{array}$ & 0.29 & 0.28 & 4390 \\
\hline Reference - hourly wage & $\begin{array}{l}\text { Difference between the reference predicted } \\
\text { by the income regression and the actual wage } \\
\text { (conditional on earning less than the reference wage) }\end{array}$ & $-0.31^{\S}$ & 0.36 & 4118 \\
\hline Part-time & Dummy: 1 if one works part-time & 0.37 & 0.48 & 12209 \\
\hline Public & Dummy: 1 if one works in public sector & 0.26 & 0.26 & 10910 \\
\hline Female & Dummy: 1 if female & 0.52 & 0.50 & 20774 \\
\hline Age & Age in years & 39.89 & 21.76 & 26774 \\
\hline Working experience full-time & Years of full-time work & 16.86 & 14.06 & 20750 \\
\hline Working experience part-time & Years of part-time work & 2.51 & 5.49 & 20750 \\
\hline Tenure & Years of working at current place & 10.63 & 9.97 & 11624 \\
\hline Education (in years) & Years of education & 12.12 & 2.69 & 19475 \\
\hline General education & Dummy for general school degree & 0.22 & 0.41 & 20774 \\
\hline University education & Dummy for at least a university degree & 0.20 & 0.40 & 20774 \\
\hline Vocational education & Dummy for a vocational education degree & 0.63 & 0.48 & 20774 \\
\hline
\end{tabular}

Notes: $\S$ : The number is defined to be positive in the regression analysis.

Other independent variables include the following dummy variables: marital status ( 5 statuses in total, including single, married with/without kids, divorced, and widowed), firm size (5), industry (9), occupation (3), and German states (16). The actual average hourly wage in this sample is $e^{2.55}=12.81$ euro. The gross average hourly wage in Germany in 2005 is 16.98 euro, covering all kinds of jobs throughout the country (own calculation, data source: OECD). The average of a higher hourly wage is $e^{0.29} \approx 1.34$ times more than the average wage in the relevant wage group. For those who earn a lower wage, on average, their hourly wage is $e^{-0.31} \approx 0.73$ of the reference wage.

The key dependent variables in the analysis are: Effort $\left(E_{i}\right)$ which is measured as hours of unpaid overtime work, and job satisfaction $\left(S_{i}\right)$ which is the answer to the question on a scale from 1 to 10 . The average score of positive reciprocity is 5.88 on a scale of 1 to 7 and the average score of negative reciprocity is 3.11 on the same scale. ${ }^{8}$ The distributions are shown in Figure 1, see also Figure 2 in Dohmen et al. (2009). Figure 2 depicts the marginal effects of relative wage changes on effort, which

\footnotetext{
${ }^{8}$ The measures for reciprocal inclinations are also stable over time. The mean and standard deviation of positive reciprocity measure in 2010 wave (number of observations: 13,418) is 5.81 (0.91), with a correlation of 0.366 (Pearson correlation coefficient, $p<0.01$ ) with the measure in 2005. Likewise, the mean and standard deviation of negative reciprocity measure is 3.03 (1.41), with a correlation of $0.48(p<0.01)$ with that measure in 2005 .
} 
will be introduced in details later. Specifically, the marginal effects are plotted by the shaded area with the distribution of reciprocity in the population; with positive reciprocity measures among workers whose earnings are higher than the peers on the left panel and negative reciprocity measures among those who earn less than their peers on the right panel. Approximately half of the respondents earn more than the average wage, as will be explained in detail in Section 3.2. Table 3 reports the Pearson correlations between important explanatory variables in the analysis. Older individuals, people with higher education, and high earners exhibit higher positive reciprocity. Low earners, males, younger people, less educated respondents, full-time workers, and private sector workers report a higher score on negative reciprocity. ${ }^{9}$

\footnotetext{
${ }^{9}$ Some of the correlations are highly consistent with Falk et al. (2016) in which middle-aged people are more positively reciprocal and women are self-reported to be less negatively reciprocal. They derive the correlations from the Global Preference Survey with 80,000 individuals from 76 countries, covering 90 percent of both the world?s population and global income.
} 
Figure 1: Marginal effect of wage on effort
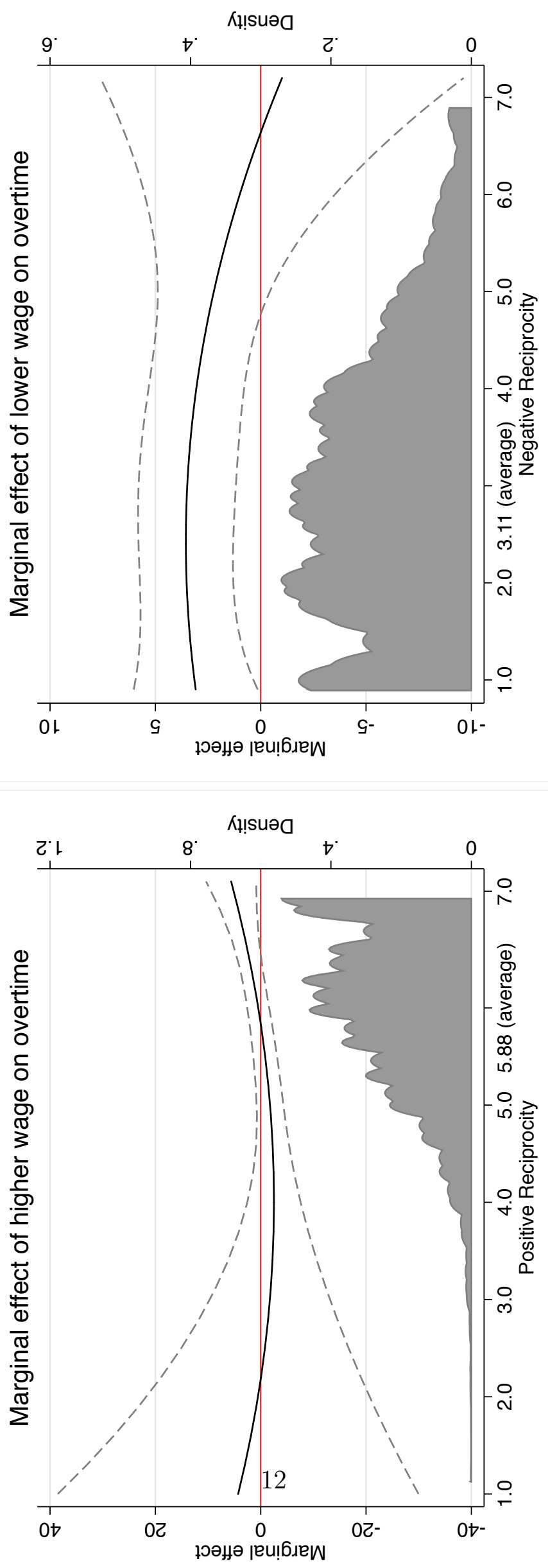
Table 3: Correlation table of important explanatory variables

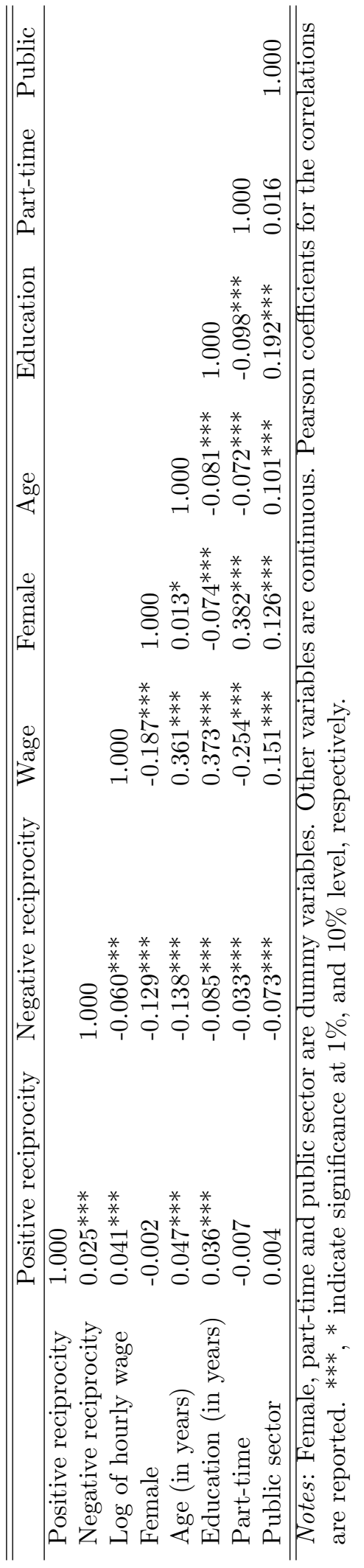


I start the analysis by developing a reference wage for each employee based on observable characteristics. I follow the literature that constructs reference wages to compare subjective well-being among similar people (for a review, see Dahlin et al. 2014). The variables in my reference wage regression are age (McBride 2001), region (Ferrer-i-Carbonell 2005), education (Clark et al. 2010), public or private sector, full-time or part-time (Van de Stadt et al. 1985), gender, industry, occupation (Clark and Oswald 1996), firm size, marital status (Dohmen et al. 2009), and higher order terms of age, education, and tenure to account for nonlinear effects. From the residuals of the income regression, I obtain a measure of how much a worker is earning more (or less) than a worker with similar characteristics in the labor market. The income regression has a typical Mincer-income equation form:

$$
\begin{aligned}
& \ln \left(y_{i}\right)=\ln \left(y_{i}^{*}\right)+\varepsilon_{i} \\
& \ln \left(y_{i}^{*}\right)=\delta D^{\prime}\left(\text { gender }_{i}, \text { age }_{i},\right. \text { education } \\
& \text {, etc. })
\end{aligned}
$$

The dependent variable income $y_{i}$ in the reference wage regression is the natural log of gross hourly income. The fitted value from the regression $y_{i}^{*}$ is thus the income a typical employee would receive. Residuals from this regression take the form of the $\log$ of the income ratio: $\ln \left(y_{i} / y_{i}^{*}\right)$. Therefore, a worker with a positive residual earns more than the reference wage, and one with a negative residual has a lower wage than the reference wage. ${ }^{10}$

Table 4 reports the regression results of the wage regression. Consistent with previous findings (such as Bonin et al 2007; Table 1 in Dohmen et al 2009) on labor income in Germany, more education is related to higher income. In contrast, being

\footnotetext{
${ }^{10}$ Residual $\varepsilon_{i}=\ln \left(y_{i}\right)-\ln \left(y_{i}^{*}\right)=\ln \left(\frac{y_{i}}{y_{i}^{*}}\right)$. Perfect prediction leads to $\varepsilon_{i}=0$ when $\frac{y_{i}}{y_{i}^{*}}=1$ so that $\ln \left(\frac{y_{i}}{y_{i}^{*}}\right)=0$.
} 
female and working part-time are related to a lower hourly wage. Age and tenure both have a concave effect on the hourly wage.

Table 4: Reference wage regression

\begin{tabular}{|c|c|}
\hline Dependent variable: Log of hourly wage & OLS \\
\hline Female & $\begin{array}{r}-0.205^{* * *} \\
(0.012)\end{array}$ \\
\hline Education (in years) & $\begin{array}{r}0.271^{* *} \\
(0.124)\end{array}$ \\
\hline Education $^{2} / 100$ & $\begin{array}{r}-1.852^{*} \\
(0.954)\end{array}$ \\
\hline Education $^{3} / 1000$ & $\begin{array}{r}0.508^{* *} \\
(0.239)\end{array}$ \\
\hline Job tenure (in years) & $\begin{array}{r}0.042^{* * * *} \\
(0.003)\end{array}$ \\
\hline Job tenure $^{2} / 100$ & $\begin{array}{r}-0.147^{* * *} \\
(0.021)\end{array}$ \\
\hline Job tenure ${ }^{3} / 1000$ & $\begin{array}{r}0.018^{* * *} \\
(0.004)\end{array}$ \\
\hline Age (in years) & $\begin{array}{r}0.079^{* * *} \\
(0.018)\end{array}$ \\
\hline $\mathrm{Age}^{2} / 100$ & $\begin{array}{r}-0.138^{* * *} \\
(0.045)\end{array}$ \\
\hline $\mathrm{Age}^{3} / 1000$ & $\begin{array}{r}0.007^{* *} \\
(0.003)\end{array}$ \\
\hline Part-time & $\begin{array}{r}-0.066^{* * *} \\
(0.014)\end{array}$ \\
\hline Public sector & $\begin{array}{r}0.042^{* * *} \\
(0.014)\end{array}$ \\
\hline Other controls & $\checkmark$ \\
\hline Constant & $\begin{array}{r}-0.304 \\
(0.593)\end{array}$ \\
\hline $\mathrm{R}^{2}$ & 0.447 \\
\hline $\mathrm{N}$ & 8508 \\
\hline
\end{tabular}

\section{$3.2 \quad$ Empirical Strategy}

In order to investigate how a worker's effort and job satisfaction are related to her reciprocal tendencies, and how this relationship depends on her relative earnings compared to similar others in the economy, I specify the following econometric model with effort ( $E_{i}$ hours of unpaid overtime) and job satisfaction $\left(S_{i}\right)$ as dependent 
variables. To ease interpretations, all variables in interactions are non-negative and measures for reciprocal tendencies are centred at their means.

I focus on the interaction terms of reciprocal tendencies and relative wages in the regression; specifically, the interaction between the measures for positive reciprocity $\left(P_{i}\right)$ and higher relative wage $\left(W_{i+}\right)$, and the interaction between the measures for negative reciprocity $\left(N_{i}\right)$ and lower relative wage $\left(W_{i-}\right) . W_{i+}$ and $W_{i-}$ are the residual terms derived from the income regression in model (1), i.e., $W_{i+}$ captures the extra wage that could not be explained by observables and $W_{i-}$ does the same for observed wage below the reference. Because the coefficients for the interaction terms capture my hypothesis, I write down the model specification in equation (2) for effort and equation (3) for satisfaction. I expect a positive sign for $\sigma_{1}$ and a negative sign for $\sigma_{2}$ in equation (2). I control for various characteristics $D_{i}$ of the employees, including age, gender, years of education, sector, part-time or fulltime job, years of work experience, firm size, occupation, industry, marital status, province of residence, higher order terms of age, education, and work experience. $\varepsilon_{i}$ captures unobserved characteristics for overtime work and job satisfaction, and are assumed i.i.d. error terms. Note that by construction, $W_{i+}$ is zero for wages below the reference wage. For these cases, $\beta_{1}$ captures the effects of positive reciprocity. We predict no effects for this case. The same holds, mutatis mutandis, for $\beta_{2}$.

To account for nonlinearity of reciprocity, I include the squared terms of reciprocity, as well as the interaction between the squared terms of reciprocity and relative earnings in equation (2). The marginal effect is plotted in Figure 1 based on equation (2) to account for nonlinearity.

$$
\begin{aligned}
E_{i}= & \sigma_{1}\left(P_{i} \times W_{i+}\right)+\sigma_{2}\left(N_{i} \times W_{i-}\right)+\sigma_{3}\left(P_{i}^{2} \times W_{i+}\right)+\sigma_{4}\left(N_{i}^{2} \times W_{i-}\right) \\
& +\beta_{1} P_{i}+\beta_{2} N_{i}+\beta_{3} P_{i}^{2}+\beta_{4} N_{i}^{2}+\theta_{1} W_{i+}+\theta_{2} W_{i-}+D_{i}^{\prime} \delta+\varepsilon_{i} .
\end{aligned}
$$


The regression for satisfaction has a similar structure. The dependent variable is self-reported job satisfaction. Respondents rank their answers from an interval from 0 to 10. This is regressed on reciprocity, relative income, and their interactions. The signs of $\eta_{1}$ and $\eta_{2}$ in equation (3) do not follow straightforwardly from theory. If employees are conditionally altruistic, I expect a positive $\eta_{1}$ and a negative $\eta_{2}$. If employees are behaving more in line with the social exchange theory, we would expect that $\eta_{1}<0$ and $\eta_{2}>0$. I also control for various characteristics $D_{i}$ of the employees. $\varepsilon_{i}$ accounts for the discrepancy between actual observed overtime work and job satisfaction and estimated values. I also include the squared terms of reciprocity, and the interactions in equation (3) to control for nonlinearity of reciprocity measures. The model is specified as follows:

$$
\begin{aligned}
S_{i}= & \eta_{1}\left(P_{i} \times W_{i+}\right)+\eta_{2}\left(N_{i} \times W_{i-}\right)+\eta_{3}\left(P_{i}^{2} \times W_{i+}\right)+\eta_{4}\left(N_{i}^{2} \times W_{i-}\right) \\
& +\gamma_{1} P_{i}+\gamma_{2} N_{i}+\gamma_{3} P_{i}^{2}+\gamma_{4} N_{i}^{2}+\kappa_{1} W_{i+}+\kappa_{2} W_{i-}+D_{i}^{\prime} \delta+\varepsilon_{i} .
\end{aligned}
$$

\section{Results}

\subsection{Reciprocity and Effort}

Table 5 reports the results on how effort is associated with employees' relative income, depending on reciprocity. Key variables of interests are the interactions between reciprocity and relative income. OLS coefficients are reported.

In general, the results show that among positively reciprocal employees, higher wages are related to more unpaid overtime hours. However, there is no evidence for a significant correlation between low wage and effort among negatively reciprocal workers.

We start with column (1) in Table 5, with only relative wages and reciprocity and their interaction terms as the explanatory variables. The coefficient for the in- 
teraction between positive reciprocity and relative wages is positive and statistically significant, showing that more unpaid work hours are related to higher earners with positive reciprocal tendencies. In contrast, the interaction between negative reciprocity and relative wages is insignificantly correlated with effort. It seems that for people with higher wage than the reference wage, the marginal effect of increased wage on unpaid overtime increases with the extent of positive reciprocity. I will further discuss the interpretation below in Figure 1.11 An average worker scores 5.88 on positive reciprocity, 3.11 for negative reciprocity; she earns 12.81 euro per hour and works 6.69 hours of overtime without payments, for more statistics see Table 2. Since in the regression, reciprocity variables are centred at their means, a worker with 1 point of positive reciprocity actually has 6.88 points $(5.88+1)$, which is close to the maximum on a scale of 7 . For such highly reciprocal workers, a $1 \%$ unit increase in hourly wage-13 euro cents-results in an increase of 2.04 minutes (0.034 hours) of unpaid overtime, an increase by $0.51 \%\left(=\frac{0.034}{6.69}\right)$ from the average of 6.69 hours per month, compared to an equally highly reciprocal worker with similar characteristics. $^{12}$

In column (2) of Table 5, I control for personal characteristics such as gender, age, education, and work related variables. In column (3) I further include other control variables such as firm size, occupation, industry, and region. The relationships persist in column (2) and (3) and the main interaction effects are very similar.

My findings are partially consistent with Dohmen et al. (2009) who regress the likelihood of doing overtime on measures of reciprocity. They do the same

\footnotetext{
${ }^{11}$ In a robustness check, I also include the interactions between positive reciprocity measures and lower earnings, that is, 'Positive reciprocity times (Reference wage - Hourly wage)'; and the interaction between negative reciprocity measures and higher earnings into the regression, that is, 'Negative reciprocity times (Hourly wage - Reference wage)'. The coefficients for these two interaction terms are insignificant. These results partly answer the N.A.s in Table 1. Results are available upon request.

${ }^{12}$ Recall that in the Mincer-form income regression, both the actual hourly wage $y_{i}$ and the reference wage $y^{*}$ take the natural logarithms. Therefore a $1 \%$ increase in the relative wage means that $y_{i}=e^{0.01} y^{*} \approx(1+0.01) y^{*}$, where $\lim _{x \rightarrow 0} e^{x} \approx 1+x$ with Taylor expansion. Since the average reference wage is 12.81 in Table 2 , an employee needs to earn an hourly wage of $12.93(1.01 \times 12.81)$ so as to increase working hours by 0.034 .
} 
Table 5: Effort and Reciprocity

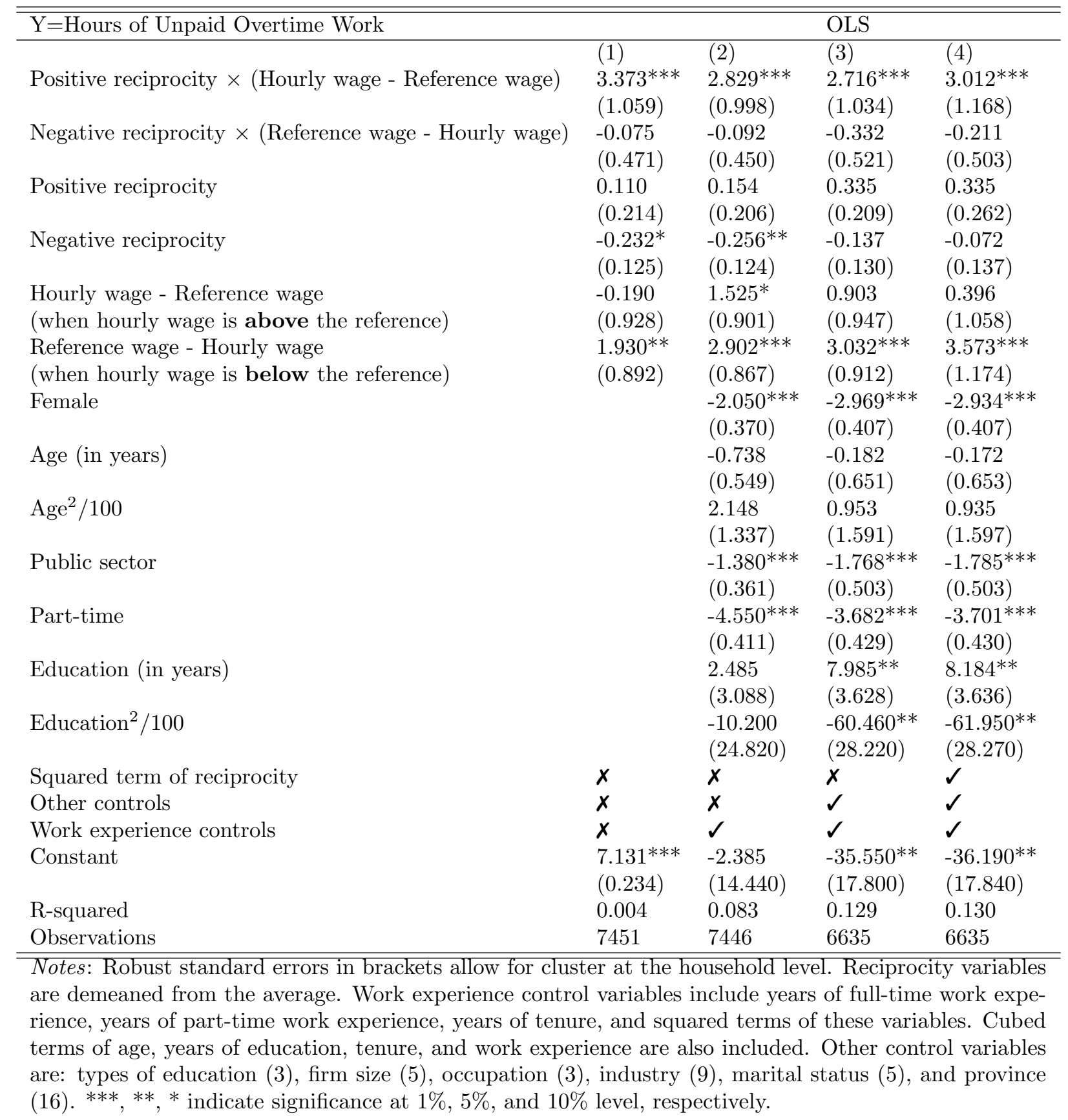


regression separately for two groups, depending on their perceptions of fair wages. Their results show that reciprocity seems to only matter when the wage is perceived to be fair: with 1 unit increase in positive reciprocity among workers who think they are receiving a fair wage, on a scale of 7 , a worker with positive reciprocity is $3.8 \%$ more willing to work overtime and a worker with negative reciprocity is $1.2 \%$ less willing to do so. However, among workers who perceive the wage to be unfair, the authors find no significant relations between reciprocity and effort.

Finally, to account for a possible nonlinear effect of reciprocity, I include squared terms of reciprocity into the regression in column (4). The main effects are very comparable to the other columns. Specifically, a $1 \%$ increase (13 cents) of the hourly income increases the unpaid overtime hours by 1.8 minutes (0.03 hours) every month, which is a $0.45 \%$ increase from the average hours of unpaid overtime.

I plot the marginal effect of having one percentage increase in income on the number of hours of unpaid overtime on the left panel of Figure 1. The marginal effects are derived from the regression coefficients from column (4) in Table 5 with a 95\% confidence interval in dashed line. In particular, this marginal effect is plotted with the distribution of positive reciprocity in the population whose earnings are higher than the peers. The graph indicates clearly that the marginal effect of higher wage on effort changes with the extent of positive-reciprocal tendencies: When positive reciprocity gets stronger, especially above the average of 5.88 , the marginal effect on effort becomes significantly positive.

The right panel of Figure 1 shows for those with a below-reference income the marginal effects of reduced income by one percentage. The marginal effect of lower wage on effort is plotted with the distribution of negative reciprocity in the population whose earnings are less than the peers. Although we observe a downward-sloping marginal effect as negative reciprocity gets stronger, the graph does not give the predicted significant negative effect. On the contrary, it shows that when negative reciprocity is below approximately 5.0, the marginal effect of 
lower wage on effort is positive. ${ }^{13}$ When negative reciprocity becomes stronger, the marginal effect becomes negative with wide confidence intervals. However, because of lack of data on employees with strong negative reciprocity, the marginal effect of having lower wages among strongly negatively reciprocal workers on effort seems insignificant.

\subsection{Reciprocity and Satisfaction}

Table 6 reports the results for job satisfaction. OLS coefficients are reported. ${ }^{14}$ The results show that job satisfaction is insensitive to the interactions between relative wage and reciprocity. The insensitivity is reflected by insignificant coefficients in front of the interaction terms. In column (2) and (3), I also control for a series of personal characteristics. The insignificance of interaction effects stays throughout the various versions of the model. The signs of the interaction terms make it difficult to pin down which theory (social exchange theory or conditional altruism) dominates.

The insignificance of the interaction between reciprocity measures and relative wages is, however, supported by the theories mentioned earlier. Because two forces (conditional altruism and social exchange) are working against each other here to determine the additional change in effort by wages for a reciprocal worker, one is conditional altruism and the other is a social exchange process; it is difficult to pin down the direction of the total effect. The positive sign for "Positive reciprocity $\times$ (Hourly wage - Reference wage)" throughout all columns in Table 6 seems to indicate that employees with high wages are more conditionally altruistic than being engaged in a social exchange process.

\footnotetext{
${ }^{13}$ This is because the marginal effect of lower wage has two parts: The interaction term "Negative reciprocity $\times($ Reference wage - Hourly wage)" and relative wage term "Reference wage - Hourly wage". In Table 5, the former is -0.211 and insignificant and the latter is 3.573 . In total, the sum gives a positive number.

${ }^{14}$ I also ran an interval regression to account for the fact that the dependent variable is both left and right censored. The results are both quantitatively and qualitatively comparable. See Appendix.
} 
Table 6: Job Satisfaction and Reciprocity

\begin{tabular}{|c|c|c|c|c|}
\hline \multicolumn{3}{|l|}{$\mathrm{Y}=$ Job Satisfaction (on a scale of 0 to 10 ) } & \multicolumn{2}{|l|}{ OLS } \\
\hline & $(1)$ & $(2)$ & $(3)$ & $(4)$ \\
\hline \multirow[t]{2}{*}{ Positive reciprocity $\times$ (Hourly wage - Reference wage $)$} & 0.025 & 0.021 & 0.065 & 0.085 \\
\hline & $(0.105)$ & $(0.106)$ & $(0.134)$ & $(0.138)$ \\
\hline \multirow[t]{2}{*}{ Negative reciprocity $\times$ (Reference wage - Hourly wage $)$} & -0.028 & -0.018 & 0.059 & 0.007 \\
\hline & $(0.068)$ & $(0.068)$ & $(0.088)$ & $(0.079)$ \\
\hline \multirow[t]{2}{*}{ Positive reciprocity } & $0.155^{* * *}$ & $0.157^{* * *}$ & $0.179 * * *$ & $0.173^{* * *}$ \\
\hline & $(0.030)$ & $(0.031)$ & $(0.034)$ & $(0.039)$ \\
\hline \multirow[t]{2}{*}{ Negative reciprocity } & $-0.129^{* * *}$ & $-0.130 * * *$ & $-0.135^{* * *}$ & $-0.147^{* * *}$ \\
\hline & $(0.018)$ & $(0.019)$ & $(0.020)$ & $(0.021)$ \\
\hline Hourly wage - Reference wage & $0.507 * * *$ & $0.528 * * *$ & $0.633^{* * *}$ & $0.599 * * *$ \\
\hline (when hourly wage is above the reference) & $(0.093)$ & $(0.094)$ & $(0.114)$ & $(0.133)$ \\
\hline Reference wage - Hourly wage & $-0.293^{* * *}$ & $-0.281^{* * *}$ & $-0.366^{* * *}$ & $-0.599^{* * *}$ \\
\hline (when hourly wage is below the reference) & $(0.097)$ & $(0.097)$ & $(0.132)$ & $(0.172)$ \\
\hline \multirow[t]{2}{*}{ Female } & & -0.071 & $-0.145^{* * *}$ & $-0.157^{* * *}$ \\
\hline & & $(0.050)$ & $(0.055)$ & $(0.056)$ \\
\hline \multirow[t]{2}{*}{ Age (in years) } & & 0.021 & 0.074 & 0.068 \\
\hline & & $(0.071)$ & $(0.090)$ & $(0.090)$ \\
\hline \multirow[t]{2}{*}{$\mathrm{Age}^{2} / 100$ (in years) } & & -0.175 & -0.338 & -0.325 \\
\hline & & $(0.164)$ & $(0.208)$ & $(0.208)$ \\
\hline \multirow[t]{2}{*}{ Public sector } & & $0.168^{* * *}$ & $0.143^{* *}$ & $0.148^{* *}$ \\
\hline & & $(0.051)$ & $(0.071)$ & $(0.071)$ \\
\hline \multirow[t]{2}{*}{ Part-time } & & -0.089 & -0.038 & -0.033 \\
\hline & & $(0.065)$ & $(0.074)$ & $(0.073)$ \\
\hline \multirow[t]{2}{*}{ Education (in years) } & & $1.487^{* * *}$ & $1.866^{* * *}$ & $1.792^{* * *}$ \\
\hline & & $(0.518)$ & $(0.627)$ & $(0.620)$ \\
\hline \multirow[t]{2}{*}{ Education $^{2} / 100$} & & $-11.690^{* * *}$ & $-14.860^{* * *}$ & $-14.280 * * *$ \\
\hline & & $(3.982)$ & $(4.722)$ & $(4.667)$ \\
\hline Squared term of reciprocity & $x$ & $x$ & $x$ & $\checkmark$ \\
\hline Other controls & $x$ & $x$ & $\checkmark$ & $\checkmark$ \\
\hline Work experience controls & $x$ & $\checkmark$ & $\checkmark$ & $\checkmark$ \\
\hline \multirow[t]{2}{*}{ Constant } & $6.968^{* * *}$ & 1.195 & -0.760 & -0.445 \\
\hline & $(0.032)$ & $(2.425)$ & $(3.059)$ & $(3.022)$ \\
\hline R-squared & 0.022 & 0.035 & 0.058 & 0.061 \\
\hline Observations & 8408 & 8402 & 7051 & 7051 \\
\hline
\end{tabular}

Notes: Robust standard errors in brackets allow for clustering at the household level. The dependent variables are the answer to questions on job satisfaction on a scale from 0 to 10 , where 0 means "completely dissatisfied" and 10 means "completely satisfied". Reciprocity variables are demeaned from the average. Work experience control variables include years of full-time work experience, years of part-time work experience, years of tenure, and squared terms of these variables. Cubed terms of age, years of education, tenure, and work experience are also included. Other control variables are: types of education (3), firm size (5), occupation (3), industry (9), marital status (5), and province (16). ${ }^{* * *},{ }^{* *}, *$ indicate significance at $1 \%, 5 \%$, and $10 \%$ level, respectively.

Nevertheless, I find that positive reciprocity is related to higher job satisfaction and negative reciprocity is linked to lower satisfaction. These relations are robust after controlling for various characteristics and with different model specifications. 
They correspond to what Dohmen et al. (2009) report about the overall success of Homo Reciprocans: for example, positively reciprocal employees have more friends and they enjoy a higher overall life satisfaction; while negative reciprocity is associated with fewer friends and lower life satisfaction.

\section{Concluding Remarks}

Employees' tendency to reward and retaliate can deeply shape the working environment and the employee-employer relationship. This paper provides quantitative evidence on the economic relevance of reciprocal tendencies, in interaction with relative wages, for work effort and job satisfaction. By comparing the wage to a reference for each employee in the economy, I find an asymmetric relation between reciprocal tendencies and effort. This not only shows the importance of reciprocal inclinations in the work place, but also how the impact differs among similar employees with different earnings. My results may be of interest to researchers in organisational psychology or management to better understand personality traits, and their consequences for labor market outcomes. Human resource policy makers might also benefit. The fact that only some employees with high earnings respond with more effort to higher wages implies that future incentive policies, i.e., performance pay, might be more effective if they target more accurately employees with specific personality traits.

Future research on reciprocity calls for causal evidence. Throughout this chapter I assume that employees know not only their own wage but also know how much workers in Germany with similar characteristics earn. This may seem a strong assumption e.g, because wage information is not always transparent, sometimes 'no disclosure contracts' even prohibit making one's wage known (Card et al. 2012). Nevertheless, the results that I find do suggest that the reference wages that I estimate matter. Of course, in additional research, one could strengthen this by 
providing explicit information about the relevant reference wage to some workers and subsequently comparing their effort and job satisfaction to a group without this explicit information. One could then also distinguish between long-run and shortrun effects. Such experiments on social comparison could be informative for the development of wage disclosure policies.

\section{Acknowledgement:}

I thank Robert Dur and Arthur Schram for their valuable comments. The dataset used in this paper was made available to me by the German Socio-Economic Panel Study (SOEP) at the German Institute for Economic Research (DIW Berlin).

\section{References}

Bellemare, Charles and Bruce S. Shearer, "Gift Exchange within a Firm: Evidence from a Field Experiment," Games and Economic Behavior, 2009 (67), 233-244.

Blau, Peter M., Exchange and Power in Social Life, New York, NY: Wiley, 1964.

Bonin, Holger, Thomas Dohmen, Armin Falk, David Huffman, and Uwe Sunde, "Crosssection Earnings Risk and Occupational Sorting: The Role of Risk Attitudes," Labour Economics, 200714 (6), 926-937.

Card, David, Mas Alexandre, Moretti Enrico, and Saez Emmenuel, "Inequality at Work: The Effect of Peer Salaries on Job Satisfaction," American Economic Review, October 2012, 102 (6), 2981-3003.

Clark, Andrew E. and Andrew J. Oswald, "Satisfaction and Comparison Income," Journal of Public Economics, September 1996, 61 (3), 359-381.

Clark, Andrew E., David Masclet, and Marie Claire Villeval, "Effort and Comparison Income: Experimental and Survey Evidence," Industrial and Labor Relations Review, April 2010, 63 (3), 407-426.

Cohn, Alain, Ernst Fehr, and Lorenz Götte, "Fair Wages and Effort Provision: Combining Evidence from a Choice Experiment and a Field Experiment," Management Science, 2014, 61 (8), 1777-1794.

Cohn, Alain, Ernst Fehr, Benedikt Herrmann, and Frédéric Schneider, "Social Comparison in the Workplace: Evidence from a Field Experiment," Journal of the European Economic Association, 2014, 00(00), 1- 22.

Dahlin, M.B., Kapteyn A., and Tassot C., "Who are the Joneses?" Cesr-Schaehher working paper No: 2014-004, 2014

de Quervain, D. J. F., U. Fischbacher, V. Treyer, M. Schellhammer, U. Schnyder, A. Buck, and E. Fehr, "Neuroscience: The Neural Basis of Altruistic Punishment," Science, 2004, 305 (5688), 1254-1257.

Dohmen, Thomas, Armin Falk, David Huffman, and Uwe Sunde, "Homo Reciprocans: Survey Evidence on Behavioural Outcomes," Economic Journal, March 2009, 119 (536), 592-612. Dohmen, Thomas, Armin Falk, David Huffman, and Uwe Sunde, "Representative Trust and Reciprocity: Prevalence and Determinants," Economic Inquiry, January 2008, 46 (1), 84-90.

Dur, Robert, Arjan Non, and Hein Roelfsema, "Reciprocity and Incentive Pay in the Work- 
place," Journal of Economic Psychology, August 2010, 31 (4), 676-686.

Falk, Armin, Urs Fischbacher, "A Theory of Reciprocity," Games and Economic Behavior, 2006, 54 (2), 293-315.

Falk, Armin, Anke Becker, Thomas Dohmen, Benjamin Enke, David Huufman, and Uwe Sunde, "The Nature and Predictive Power of Preferences: Global Evidence," Working paper, 2016.

Fehr, Ernst and Lorenz Götte, "Do Workers Work More if Wages are High? Evidence from a Randomized Field Experiment," American Economic Review, March 2007, 97(1), 298-317.

Fehr, Ernst and Simon Gächter, "Cooperation and Punishment in Public Goods Experiments," American Economic Review, September 2000, 90 (4), 980-994.

Ferrer-i-Carbonell Ada, "Income and Well-being: An Empirical Analysis of the Comparison Income Effect," Journal of Public Economics, 2005, 89 (5), 997-1019.

Festinger, Leon, "A Theory of Social Comparison Processes," Human Relations, 1954, 7, 117 ?140. Gneezy, Uri, John List, "Putting Behavioral Economics to Work: Testing for Gift Exchange in Labor Markets Using Field Experiments," Econometrica, September 2006, 74(5), 1365-1384.

Gollwitzer, Mario, Milena Meder, and Manfred Schmitt, "What Gives Victims Satisfaction When They Seek Revenge?," European Journal of Social Psychology, 2011, 41 (3), 364-374.

Knutson, Brian, "Sweet Revenge?," Science, 2004, 305 (5688), 1246-1247.

Kube, Sebastian, Michel Andre Marechal, and Clemens Puppe, "The Currency of Reciprocity: Gift Exchange in the Workplace," American Economic Review, June 2012, 102 (4), 164462 .

Levine, David K., "Modelling Altruism and Spitefulness in Experiments," Review of Economic Dynamics, 1998, 1, 593-622.

Mas, Alexandre, "Pay, Reference Points, and Police Performance," The Quarterly Journal of Economics, 2006, 121 (3), 783-821.

McBride, M. "Relative-income Effects on Subjective Well-being in the Cross-section," Journal of Economic Behavior and Organization, 2001, 45 (3), 251-278.

Montizaan, Raymond, Andries de Grip, Frank Cörvers, and Thomas Dohmen, "The Impact of Negatively Reciprocal Inclinations on Worker Behavior: Evidence from a Retrenchment of Pension Rights," Management Science, March 2016, 62 (3), 668-681.

Shapiro, Carl and Joseph E. Stiglitz, "Equilibrium Unemployment as a Worker Discipline Device," American Economic Review, 1984, 433-444.

van de Stadt, Huib, Arie Kapteyn, and Sara van de Geer, "The Relativity of Utility: Evidence from Panel Data," The Review of Economics and Statistics, May 1985, 67 (2), 179-187. 


\section{Appendix}

Table 7: Job Satisfaction and Reciprocity: Interval Regression

\begin{tabular}{|c|c|c|c|c|}
\hline \multicolumn{3}{|l|}{$\mathrm{Y}=$ Job Satisfaction (on a scale of 0 to 10$)$} & \multicolumn{2}{|l|}{ OLS } \\
\hline & $(1)$ & $(2)$ & (3) & (4) \\
\hline Positive reciprocity $\times$ (Hourly wage- Reference wage) & 0.025 & 0.030 & 0.066 & 0.087 \\
\hline \multirow{2}{*}{ Negative reciprocity $\times$ (Reference wage - Hourly wage $)$} & $\begin{array}{l}-0.1008) \\
-0.028\end{array}$ & $\begin{array}{l}(0.100) \\
-0.021\end{array}$ & $(0.133)$ & $\begin{array}{l}-0.136) \\
-0.001\end{array}$ \\
\hline & $(0.068)$ & $(0.068)$ & $(0.089)$ & $(0.079)$ \\
\hline \multirow[t]{2}{*}{ Positive reciprocity } & $0.155^{* * *}$ & $0.155^{* * *}$ & $0.178^{* * *}$ & $0.172^{* * *}$ \\
\hline & $(0.030)$ & $(0.031)$ & $(0.034)$ & $(0.039)$ \\
\hline \multirow[t]{2}{*}{ Negative reciprocity } & $-0.129 * * *$ & $-0.128^{* * *}$ & $-0.133^{* * *}$ & $-0.144^{* * *}$ \\
\hline & $(0.018)$ & $(0.019)$ & $(0.020)$ & $(0.021)$ \\
\hline \multirow[t]{2}{*}{ Hourly wage - Reference wage } & $0.507^{* * *}$ & $0.530^{* * *}$ & $0.630^{* * *}$ & $0.597^{* * *}$ \\
\hline & $(0.093)$ & $(0.094)$ & $(0.113)$ & $(0.132)$ \\
\hline \multirow[t]{2}{*}{ Reference wage - Hourly wage } & $-0.293^{* * *}$ & $-0.287^{* * *}$ & $-0.373^{* * *}$ & $-0.619 * * *$ \\
\hline & $(0.097)$ & $(0.098)$ & $(0.132)$ & $(0.172)$ \\
\hline \multirow{2}{*}{\multicolumn{2}{|c|}{ Female }} & $-0.087^{*}$ & $-0.161^{* * *}$ & $-0.173^{* * *}$ \\
\hline & & $(0.049)$ & $(0.055)$ & $(0.055)$ \\
\hline \multirow{2}{*}{\multicolumn{2}{|c|}{ Age (in years) }} & $-0.098^{* * *}$ & $-0.119 * * *$ & $-0.120 * * *$ \\
\hline & & $(0.019)$ & $(0.024)$ & $(0.024)$ \\
\hline \multirow{2}{*}{\multicolumn{2}{|c|}{$\mathrm{Age}^{2} / 100$}} & $0.105^{* * *}$ & $0.121^{* * *}$ & $0.122^{* * *}$ \\
\hline & & $(0.021)$ & $(0.027)$ & $(0.026)$ \\
\hline \multirow{2}{*}{\multicolumn{2}{|c|}{ Public sector }} & $0.158^{* * *}$ & $0.142^{* *}$ & $0.147^{* *}$ \\
\hline & & $(0.051)$ & $(0.071)$ & $(0.071)$ \\
\hline \multirow{2}{*}{\multicolumn{2}{|c|}{ Part-time }} & $-0.114^{*}$ & -0.054 & -0.050 \\
\hline & & $(0.063)$ & $(0.072)$ & $(0.071)$ \\
\hline \multirow{2}{*}{\multicolumn{2}{|c|}{ Education (in years) }} & -0.031 & -0.143 & -0.144 \\
\hline & & $(0.086)$ & $(0.122)$ & $(0.121)$ \\
\hline \multicolumn{2}{|l|}{ Education $^{2} / 100$} & 0.242 & 0.643 & 0.650 \\
\hline Squared term of reciprocity & $x$ & $x$ & $x$ & d \\
\hline Other controls & $x$ & $x$ & $\checkmark$ & $\checkmark$ \\
\hline Work experience controls & $x$ & $\checkmark$ & $\checkmark$ & $\checkmark$ \\
\hline Constant & $\begin{array}{l}0.664^{* * *} \\
(0.009)\end{array}$ & $\begin{array}{l}0.658^{* * *} \\
(0.009)\end{array}$ & $\begin{array}{l}0.642^{* * *} \\
(0.010)\end{array}$ & $\begin{array}{l}0.641^{* * *} \\
(0.010)\end{array}$ \\
\hline Log pseudolikelihood & -17510.667 & -17452.112 & -14533.508 & -14524.102 \\
\hline Observations & 8408 & 8402 & 7051 & 7051 \\
\hline
\end{tabular}

Notes: Robust standard errors in brackets allow for clustering at the household level. The dependent variables are the answer to questions on job satisfaction on a scale from 0 to 10 , where 0 means "completely dissatisfied" and 10 means "completely satisfied". Interval regression is performed to account for the fact that the dependent variable is both left- and right- censored. Reciprocity variables are demeaned from the average. Work experience control variables include years of full-time work experience, years of part-time work experience, years of tenure, and squared terms of these variables. Cubed terms of age, years of education, tenure, and work experience are also included. Other control variables are: types of education (3), firm size (5), occupation (3), industry (9), marital status (5), and province (16). ${ }^{* * *},{ }^{* *},{ }^{*}$ indicate significance at $1 \%, 5 \%$, and $10 \%$ level, respectively. 